\title{
Research on the Improvement of Road and Bridge Construction Efficiency
}

\author{
Wang Yanhao \\ The 14th Metallurgical Construction Corporation of China Nonferrous Metal Industry, China, \\ 650000
}

Keywords: road and bridge; Structural disease; traffic accident; reinforcement technology

\begin{abstract}
As one of the important people's livelihood projects in China, the construction of road and bridge engineering is closely related to urban modernization. However, after the road bridges were developed and used in the city, there were more structural problems. For example, there were many cracks on the surface of the bridges, which affected the aesthetics of the bridge buildings. On the other hand, the safety was reduced, and roads were more likely to cause roads. Traffic accidents occur. This paper presents practical suggestions on the improvement of efficiency by elaborating the common problems in road and bridge construction for readers' reference.
\end{abstract}

\section{Introduction}

In the early stage of bridge construction in our country, the design and construction concept of the bridge was rather old, so there are often phenomena such as small diameter of the steel bar and small parts. In the future use, road bridges are greatly affected by atmospheric corrosion and temperature factors, which leads to their own service life and quality and safety. Strengthening and rebuilding the safety hazards of old bridges can improve the ability of road bridges to pass through, and can also effectively extend their service life, thus further promoting the development of bridge construction.

\section{Common problem of road bridges}

\subsection{Uneven settlement of road and bridge foundation}

The uneven settlement of road and bridge foundations is one of the more common quality problems in the use of roads and bridges in China. Such problems can lead to structural instability of roads and bridges, which can easily lead to cracks on the surface of roads and bridges, and can also lead to collapse problems. . There are many factors that affect the uneven settlement of roads and bridges. The construction unit must do timely remedial measures in the initial stage of uneven settlement of the foundation to avoid excessive losses. At present, some of the construction units in China do not have sufficient supervision over the foundations, which lead to the personnel in the construction process failing to follow the requirements. The quality of the construction process is not well controlled, and it is also one of the important reasons for the uneven settlement of the 
foundation.

\subsection{Cracks in bridge deck pavement}

Cracks on the surface of roads and bridges are also common in engineering construction. There are many causes of surface cracks in roads and bridges. For example, the sudden braking in the process of driving the vehicle will cause the road and bridge to bear more loads. In the long term, the road bridge surface will be squeezed too much, which will cause wear on the road surface, and thus produce more cracks. In addition, the technical level of the staff in the construction process is not sufficient enough, which leads to more safety hazards in the work. The non-standard operations also lead to cracks on the surface of roads and bridges. At present, road and bridge paving layers of our country are mostly semi-rigid structures, which have a certain role in helping to increase the compaction strength of paving layers. However, they have obvious changes in temperature. The temperature difference in weak construction environments is relatively large, and cracks are more likely to occur.

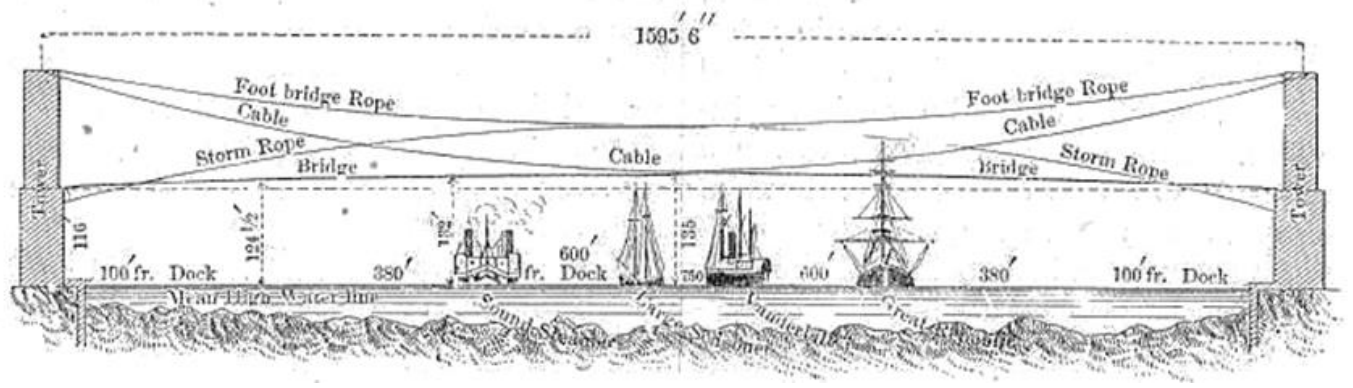

Fig.1 Classic road and bridge construction legend

\subsection{Road and bridge erosion problems}

The main reason for the erosion of road bridges lies in the geographical environment and human factors. The appearance of cellular structures or layered flaking on the pavement surface of road bridges not only affects the overall appearance, but also exposes the steel bars in roads and bridges, causing corrosion and deterioration of the overall structure.

\section{Solutions to Common Diseases of Roads and Bridges}

\subsection{First set up a waterproof insulation layer at the pier}

The primary task of solving the common diseases of road bridges is to install a water-retaining and temperature-resisting layer at the bridge piers, and use a certain thickness of PE plate to wrap around on the four sides and cover them with furnace ash. Taking the small thermal conductivity of the furnace ash as the key point to prevent the freezing damage of the pier.
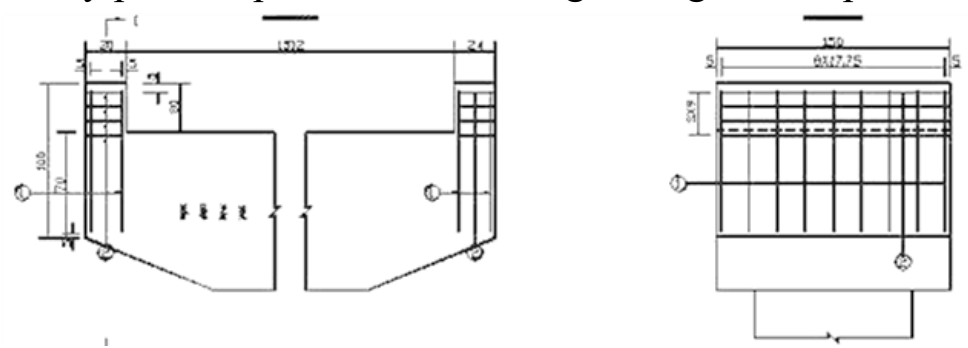

Fig.2 Road and Bridge Construction Efficiency Improvement Legend 


\subsection{Brush asphalt paint isolation layer}

By brushing the bituminous insulation layer, the permafrost can be used to reduce the degree of extrusion of the foundation structure, and to some extent avoid frost heave, and the asphalt or butter can be thickly coated on the bridge foundation layer. The contact surface between the foundation of the road bridge and the soil can be changed. Adding a certain amount of salt in the backfill can turn the ordinary soil into saline soil, which can further reduce the temperature at which the soil reaches frost heave.

\subsection{Structural system adjustments}

To change the structure and system of roads and bridges within the urban area, we must first increase the number of bridges, reduce the overall bridge span, and reduce the tensile stress generated by the bridge as much as possible so as to improve the carrying capacity. This approach is also the addition of bridge piers as a new fulcrum for the architecture. This method requires attention that the bridge hole after the completion of the reinforcement of the bridge can further meet the needs of navigation or traffic.

\section{Direct reinforcement methods can effectively improve the efficiency of road and bridge construction}

\subsection{Increase the section reinforcement method}

Concrete reinforcement is carried out on the bearing pressure area of the curved members of the road bridge. On the one hand, the cross-sectional area and height in the pressure-bearing area can be increased, and on the other hand, the bridge stiffness is constructed on the overall mechanical point of view, including the bridge resistance of the normal section. Bending ability and shear stress capability of oblique section. When using this method, the general process method is simpler, the construction technology is more mature, and the overall adaptability is stronger. This method can be used for the reinforcement of walls and columns.

\subsection{Concrete displacement reinforcement method}

The concrete replacement method is mainly used to reinforce the confined area of the bridge, because the circumference of the fan shape $=$ radius $\times 2+$ arc length, if the radius is $r$, the diameter is $\mathrm{d}$, the degree of the central angle of the fan-shaped pair is $\mathrm{n}^{\circ}$, then Bridge pier pierced perimeter:

$$
\mathrm{C}=2 \mathrm{r}+(\mathrm{n} \div 360) \pi \mathrm{d}=2 \mathrm{r}+(\mathrm{n} \div 180) \pi \mathrm{r}
$$

You can also divide the area of the circle where the fan is located by 360 and multiply the angle of the center angle of the fan.

$\mathrm{N} \mathrm{S}=\mathrm{NPR}^{\wedge} 2 / 360 \mathrm{~S}=1 / 2 \mathrm{LR}$ ( $\mathrm{L}$ is the arc length, $\mathrm{R}$ is the radius)

This approach is itself very much aimed at beams with relatively obvious quality defects or with low strength, and its advantages can be significantly achieved after reinforcement, that is, there is no impact on the net space of the building after the completion of the work. The disadvantages are also obvious, that is, although the defective columns in the pressure zone of the bridge are reinforced, the wet operation time is still longer. 


\subsection{Outer wrapping profile reinforcement method}

The overwrapped material reinforcement method is used to wrap and bond the steel plate or profile and fix it on the periphery of the construction requiring reinforcement. In the design of reinforced concrete structures, wet outsourcing reinforcement techniques can be used. The steel selected in the construction process can be bonded by the epoxy resin grouting technology, so that the overall reinforcement construction can be formed around the building to achieve the purpose of strengthening the components. After the completion of the reinforcement measures, the pressure bearing structure under the action of the profiled steel and the reinforced elements has greatly improved the overall pressure bearing capacity. This method is relatively simple and easy, and the force is reliable and the overall workload is small.

\subsection{Outer wrapping fiber plastic reinforcement method}

Similar to the former, the method of reinforcing the outer wrapping fiber and plastic is also to wrap and stick the composite reinforcing material with a certain rigidity, and concentrate on the stress area for reinforcement to form a community under pressure and tension, and the overall reinforcement and reinforcement is constructed. Load capacity. This kind of reinforcement technology has the advantages of the original profile reinforcement technology on the one hand, and it is more resistant to moisture and corrosion resistance on the other hand, and the maintenance cost is lower. It is mainly applicable when concrete components are subjected to various stress extrusions.

\section{Summary}

As one of the important livelihood projects in China, the construction of road and bridge projects is closely related to the modernization of the city. However, after the road bridges were developed and used in the city, there were more structural problems. The road bridges were greatly affected by atmospheric corrosion and temperature factors, which led to their own service life and quality and safety. For the reconstruction and maintenance of road bridges that have already been completed, maintenance is mainly carried out through the replacement of some important components of the bridges, and related plans are formulated according to the technology used in the construction and the current bearing capacity of the road bridges. Organize and improve the roads and bridges as a whole.

\section{References}

[1] Kamaitis Z. Influence of functionally obsolete bridges on the efficiency of road network. Part I: obsolescence characteristics and assessment[J]. Baltic Journal of Road \& Bridge Engineering, 2012, 7(3):173-180.

[2] Ying-Ying H U. Research on Road and Bridge Whole Process Cost Control Under BIM Technology[J]. Construction \& Design for Engineering, 2017.

[3] Gao J H. Analysis of soft soil foundation construction technology in road and bridge construction[J]. Heilongjiang Science, 2017. 